\title{
Perspectives of Aboriginal issues among non-Aboriginal residents of rural Victorian communities
}

Lisa Bourke* is Director of the University Department of Rural Health at The University of Melbourne. Trained as a rural sociologist, she has experience in social research in rural communities across Australia and the U.S. Her research interests focus on social inclusion, the development of rural health as a discipline and power relations in rural communities.

*Corresponding author: bourke@unimelb.edu.au; (03) 5823 4519; PO Box 6500 Shepparton, 3614

Christina Malatzky is a sociologist and social researcher at the Department of Rural Health, The University of Melbourne. Her research interests focus on cultural inclusion, gender and the application of Foucault to rural health.

Daniel Terry is a nurse, social researcher and clinical researcher at the Department of Rural Health, The University of Melbourne. His research interests focus on the effective management of chronic illnesses in rural areas as well as recruitment and retention issues among the rural health workforce.

Raelene Nixon is a Gungarri descendant with experience working in Aboriginal community development, health, education and research. Based at the Department of Rural Health, The University of Melbourne, she is embarking on a $\mathrm{PhD}$ focused on repositioning the value of Indigenous people in the Goulburn Murray region.

Karyn Ferguson is a Yorta Yorta woman and researcher with experience conducting research in maternal and child health and dedicated to the wellbeing of Aboriginal children. Her role at the Department of Rural Health, The University of Melbourne combines community engagement and research. She is embarking on a $\mathrm{PhD}$ focusing on culturally safe models of birthing.

This is the author manuscript accepted for publication and has undergone full peer review but has not been through the copyediting, typesetting, pagination and proofreading process, which may lead to differences between this version and the Version of Record. Please cite this article as doi: $10.1002 /$ ajs4.16

This article is protected by copyright. All rights reserved 
Peter Ferguson is Yorta Yorta man with a focus on education in rural communities for Aboriginal people. His role at the Department of Rural Health, The University of Melbourne has supported a range of Aboriginal students into and through university courses while based in their rural community with outcomes for the students' community.

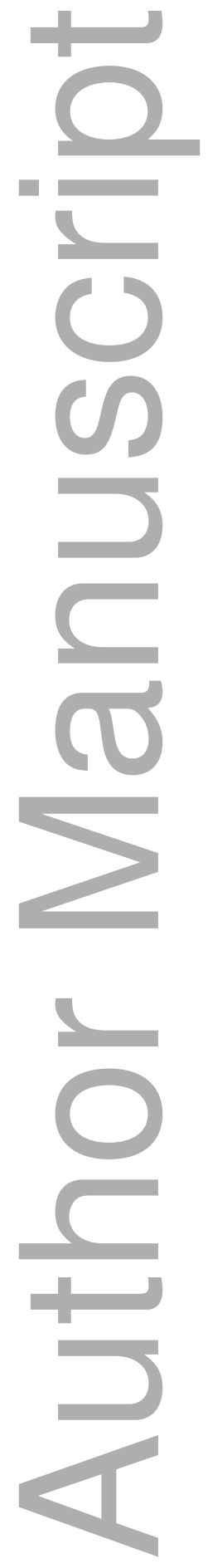




\section{Article Type: Original Article}

\section{Perspectives of Aboriginal issues among non-Aboriginal}

\section{Residents of rural Victorian communities}

(5)

\section{Abstract}

Racism, in various forms, remains a dominant feature in Australian society. Aboriginal Australians are commonly targets of racial discrimination. However, understanding racism is difficult given that racial attitudes vary towards particular groups of people, across place and time and are difficult to measure. This paper presents responses of residents across four rural shires in Victoria to questions about attitudes towards Aboriginal people/issues. Responses indicated that attitudes towards Aboriginal people were diverse and that individuals varied in their attitudes on specific items. There were subtle differences between the four sites and association between demographic characteristics and some items in particular sites. This suggests that respondents are inconsistent in their attitudes relating to Aboriginal people/issues and that there are place-based influences on these attitudes. We conclude that the many varied understandings of racism and Aboriginal Australians allow the discourses of exclusion, disempowerment and othering to be maintained.

Key Words: Racism, Aboriginal Australians, Anti-racism, Attitudes towards Aboriginal people, Rural

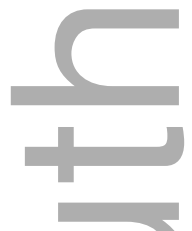

\section{Introduction}

Scholarship, public debates and awareness campaigns in health, work environments, public spaces, football arenas, justice systems, child welfare and our constitution confirm that racism is very much alive within Australia (Henry et al. 2004; Pedersen et al. 2006; Forrest \& Dunn 2007; Paradies et al. 2008; Paradies 2016; Maddison 2011; Nelson 2013; Beyond Blue 2014; Hage 2014). Research has found that one in five Australians have reported experiencing discrimination based on skin colour, ethnic origin or religion (VicHealth 2014). Most Australians recognise that racism is a problem but fewer recognise the privileged 
position of Anglo Australians (VicHealth 2014; Dunn \& Nelson 2011). Research has found that Aboriginal Australians report experiencing interpersonal racism as a 'part of daily life' (Larson et al. 2007: 326; Beyond Blue 2014; Deitch et al. 2003; Forrest \& Dunn 2007; Hage 2014; Paradies et al. 2008; VicHealth 2014). The everydayness of racial discrimination in Australia make it easier for those who do not experience it to dismiss it as a national concern (see Forrest \& Dunn 2007: 706). In these ways, racist attitudes, beliefs and behaviours have become normalised (see Hage 2014).

While routine, the impacts of experiencing racism are significant (Paradies et al. 2008). Various studies have reported on connections between routine experiences of interpersonal racism, prolonged stress and its consequences for physical and mental wellbeing (Wyatt et al. 2003; Larsen et al. 2007; Jordan et al. 2010). The impacts of experiencing racism are significant and range from reduced and unequal access to resources, to increased exposure to risk factors, coping behaviours such as smoking, alcohol and other drug use, impacts on the immune, endocrine and cardiovascular systems, stress and negative emotional responses, physical assault, mental ill-health and suicidality (Paradies et al. 2008). Paradies (2006) found that experiences of interpersonal racism by Aboriginal Australians were reliable gauges for poor mental and physical health outcomes.

In a survey in one of the regions of this study, most Aboriginal respondents living in Greater Shepparton reported 'experiencing at least one racist incident' in the past year and almost eight in ten had been exposed nine or more incidents (City of Greater Shepparton, 2011: 1). Consistent with other research (Paradies 2006), these experiences were encountered in many different settings, including while shopping, in public places, engaging with educational institutions and in sport and recreational activities. One in five indicated that they actively avoid certain situations in their daily lives to elude experiences of racial discrimination and half reported that 'racism has affected their life to either a great or moderate extent' (City of Greater Shepparton, 2011: 2-3).

The presence and impact of racism towards Aboriginal people makes understanding racial attitudes important. Paradies et al. (2008) call for more research on the prevalence of racism and the nature of racism for different groups. Specific studies take the issue beyond racism generally to the relationships between groups in particular places. In this way, locally generated data can have powerful impact in demonstrating how local people and local structures are implicated in this nationwide phenomenon. This paper explores attitudes towards Aboriginal people/issues among non-Aboriginal residents of four rural Shires in 
Victoria. It aims to (i) explore attitudes towards Aboriginal people/issues among nonAboriginal residents in these rural areas, and (ii) identify differences in attitudes towards Aboriginal people/issues across these rural regions and between demographic characteristics of respondents. To begin, an overview of Australian studies on racism and racial attitudes is presented.

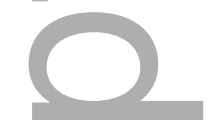

\section{Literature on attitudes among rural residents towards Aboriginal people and issues}

\section{Where do these attitudes come from? Understandings of racism in Australia}

Underpinning attitudes towards Aboriginal people and Aboriginal issues are various discourses of race relations in Australia (Dunn et al. 2004; Grattan 2000; Maddison 2011, Nelson 2014). Current literature suggests that racist attitudes are, in part, sustained through the continuing dominance of 'false belief' discourses, which construct an 'us versus them' mentality. Through these discourses, stereotypes work to undermine the understanding of persistent and systemic racism (Forrest \& Dunn 2007). For example, appealing to the ideology of Australian fairness and equality, the discourse of sameness reflects a belief that all people can be treated the same, thereby dismissing cultural, social, identity and gender differences and catering for the perceived norm (Bourke \& Geldens 2007; Dunn \& Geeraert 2003; McCallun 2003). The dominant assumption is that the 'problem' resides with being different from this perceived norm, and thus the onus is on 'the different', in this case Aboriginal people, to change. The myth of 'special privilege' is also prevalent in Australia where parallel systems have created the belief that Aboriginal people get more benefits than non-Indigenous Australians (Henry et al. 2004; McCallum 2003). A significant relationship has been found between beliefs in 'special treatment' and negative attitudes towards Aboriginal Australians in particular (see Pedersen et al. 2005; Pedersen et al. 2006). Together, these discourses identify cultural differences in strategies used to prejudice Aboriginal Australians while simultaneously denying cultural differences to maintain inequity and disempowerment.

Nelson $(2013: 93 ; 100)$ documents four dominant discourses of denial that operate today. The first is absence or outright denial of racism. Because outright racist comments are less socially acceptable than they were in the past, strategies are used to minimise/justify them and actors carefully construct their views as 'balanced and rational' (Nelson 2013: 90) 
from within their own cultural position. The second is one of temporal deflections, such as there is less racism today than there was in the past. The third is spatial or localised deflections; for example, racism is 'not a problem around here', particularly evident in rural centres where some are identified as 'racist' hubs or the unsubstantiated belief that rural Australians are more racist than urban residents. The final discourse is deflection from mainstream, such that racism is not an 'overwhelming problem' but only perpetuated by a few (Nelson 2013).

Authors have also identified 'older' and 'newer' forms of racism (Forrest \& Dunn 2007; Hage 2014; Pedersen et al. 2004; Walker 2001). 'Old racisms' centre on discourses of inferiority and inequality. They include arguments for racial segregation, the belief that some ethnic groups are somehow superior to others and that there are 'natural' differences between ethnic groups that support these propositions (Forrest \& Dunn 2007: 705). It is generally agreed that old racisms now co-exist with newer, yet more powerful forms of racism (Forrest \& Dunn 2007: 705). Denial and deflection are prevailing themes within these modern racisms. These newer forms of racism are subtle (see Gainous 2012) and difficult to pinpoint, articulate and act upon (see Cunneen et al. 2014; Hage 2014). Measures of old and new racisms yield different results and are not consistently related (Pedersen et al. 2004).

This study seeks to understand the attitudes held by non-Aboriginal populations about Aboriginal people and issues and attempts to situate these attitudes within particular discourses. Before this, a review of Australian studies focusing on attitudes towards Aboriginal people/issues are reviewed.

\section{Attitudes towards Aboriginal Australians}

While difficult to measure (Paradies et al. 2008), there have been studies of racial attitudes in Australia (Dunn et al. 2004; Paradies 2016; VicHealth 2014). In a survey of 1,000 Australians, it was found that: 'discrimination against Indigenous Australians is considered common' and one in five people would 'move away if an Indigenous Australian sat near them' (Beyond Blue 2014: 2). Many Australians were also found to subscribe to negative stereotypes, including that Aboriginal people receive 'special privileges' (almost half of those surveyed), are lazy (one-third of those surveyed) and 'should behave more like 'other Australians" (almost one-third of those surveyed). It was also found that 'many do not recognise examples of discriminatory behaviour as forms of discrimination', such as moving away from an Aboriginal person who sits near them (almost half) or verbal abuse (10\%). The 
likelihood that Australians will intervene when they encounter discrimination is not high (just over half of those surveyed) and few respondents demonstrated an understanding of the impact of discrimination (Beyond Blue 2014). From July 2014, a nationwide campaign to raise awareness about the discrimination aired television commercials in Victoria, which named moving away from an Aboriginal person on a bus as racist (Beyond Blue 2014).

In another study, VicHealth (2014) found that while the majority of Victorians agreed that Aboriginal people hold a special place as the First Australians, more should be done to reduce race-based discrimination. Further most agreed that all Victorians should be expected to treat others from racial or ethnic groups fairly. Almost half agreed that Aboriginal people get more government money than they should. Other studies have confirmed that around half of Australians believe Aboriginal people are treated over-generously by the government (Dunn \& McDonald, 2001). Previous research found that at least one-quarter of NSW and Victorian residents would be concerned if a close relative were to marry an Indigenous person (Paradies et al. 2008; Dunn et al. 2003). Many of these studies contend that both old and new racisms exist but among different people and one form of racism does not predict the other (Dunn \& McDonald, 2001; Dunn et al. 2004; Habtegiorgis et al. 2014; Pedersen et al. 2004).

Studies of racial attitudes in Australia have also found that older people tend to have more negative attitudes of racism (Pedersen et al. 2004; Dunn et al. 2004). Older people and those with lower education levels have been found to hold more assimilationist views (Dunn et al. 2004). Levels of formal education have also been found to influence attitudes towards Aboriginal Australians; those with lower levels of formal education tend to be more racist (Pedersen 2004). There is limited evidence that men may express more racist attitudes towards Aboriginal people than women (Dunn et al. 2004). In a study of attitudes towards racial groups, education, age and gender were found to correlate with particular attitudes but each correlated with different attitudes (Dunn et al. 2004) suggesting complexity around who holds negative perspectives. On the other hand, empathy has been found to influence attitudes towards Aboriginal people and education about Aboriginal issues/history has been found to influence anti-racism attitudes (Pedersen 2004).

Research has found that different 'outgroups' experience different types of racism and by different people. Further, this can vary for different places (Dunn \& McDonald 2001; Forrest \& Dunn 2006; Habtegiorgis et al. 2014; VicHealth 2014). For example, Dunn and McDonald (2001) found that respondents had varying views on migration, cultural diversity, 
government support to Aboriginal people and continuation of the Aboriginal and Torres Strait Islander Commission, including that there were place effects in these attitudes. Therefore, racial attitudes toward Aboriginal people is likely to be distinct from attitudes towards other groups. Detailed analysis of attitudes toward specific groups in particular locations is required (Paradies et al. 2008).

Earlier studies implied that residents of rural regions of Australia were more racist than urban residents. However, further exploration found that types of racism varied between rural and urban Australia and that there was more variation within rural and urban areas (Dunn \& Geeraert 2003; Dunn \& McDonald 2001). Racism varies depending on definitions of racism, local history, local economy and affluence, and local anti-racist messages so that '...the nature and frequency of racisms is more likely related to the manner in which these factors combine in unique ways in each region and create historically geographically specific ideologies of racism' (Dunn \& McDonald 2001: 41; see also Dunn \& Geeraert 2003). Dunn $\&$ McDonald suggest that 'while racism is everywhere, it is also possible that racism is 'everywhere different' ' (2001: 30; see also Kobayashi \& Peake 2000). Interaction of cultures occurs in specific spaces that are negotiated through racial interactions in these communities (Wise 2010). Despite local variations, racism is often discussed as a national issue and anti-racial strategies have been largely homogenous (Dunn \& McDonald 2001). Locally developed anti-racism campaigns could be more effective (Dunn \& Geeraert 2003).

This paper adopts a local focus and explores the perspectives of rural residents about Aboriginal people/issues. It attempts to identify who is more likely to hold particular attitudes and if there are differences across four rural shires. This contributes to understanding perceptions of a broad range of people from specific places in their attitudes towards Aboriginal people.

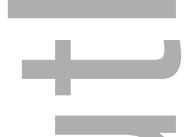

\section{Methods}

As part of a study of health, racism was included as a topic of inquiry. The study was conducted in four rural, local government areas of Victoria, namely Greater Shepparton, the Rural City of Wangaratta, Moira Shire and Central Goldfields Shire. The first two are the areas around Shepparton and Wangaratta, respectively, which each have a regional centre and larger populations than the other two Shires. Moira and Central Goldfields shires are more rural with multiple small towns but further travel to a regional centre. Greater Shepparton, Moira and the Rural City of Wangaratta are located in northeast Victoria while Central 
Goldfields Shire sits in the central-western region of the state. Greater Shepparton has a larger proportion of Aboriginal and Torres Strait Islander residents while this proportion is lower in Wangaratta and Central Goldfields.

Following approval from The University of Melbourne Human Ethics Committee, a questionnaire was distributed to 5,000 households randomly selected from the telephone directory (2,000 in Greater Shepparton and 1,000 in the other Shires). The envelope and letter introducing the study was addressed to the individual listed in the telephone directory. Two weeks after the initial mailing in September 2014, a postcard reminder was mailed to each household in October. In November, another questionnaire was mailed to households which had not returned the questionnaire (Dillman 2000). A large number of questionnaires were returned undelivered and 1,269 were returned complete, resulting in a participation rate of $35 \%$. Given the sample relied on landlines listed in a telephone directory, respondents tended to be older, male and longer-term residents. Only a small number $(n=25)$ of questionnaires were completed by respondents identifying as Aboriginal and/or Torres Strait Islander. Given this small proportion, they were excluded from analysis to focus on the perspectives of non-Aboriginal Australians. As a result, 1,244 questionnaires were analysed.

The questionnaire asked a series of demographic questions, including gender (male/female), age (in years), length of residence in the local community (in years), Indigenous status (Aboriginal/Torres Strait Islander or not), born in Australia (yes/no), English as first language (yes/no), level of education (less than Year 12 or Year 12/further education), rurality (live in a large town, small town or on a property/farm) and income (less than $\$ 799$ per week or $\$ 800$ a week or more).

While attitudinal measures are only indicators, they influence individual behaviours and the reproduction of social norms and cultures. Attitudes towards particular groups suggest thought-processes, behaviours and contributions to reproducing/resisting responses to these groups (VicHealth 2014). Given that racism and disrespect is determined by the perceptions of those offended, in this study measures of attitudes towards Aboriginal Australians were designed by Aboriginal researchers based on their perceptions of racism and previous research. These researchers wanted to focus on different dimensions of racial attitudes, including local and non-local issues, on personal and political issues, current media discussions and thinking behind how people viewed race. There was lengthy debate among three Aboriginal researchers about how to best develop survey questions on race and other measures were reviewed (see 
Dunn \& McDonald 2001; McCallum 2003; Paradies et al. 2008; Pederson et al., 2004;

VicHealth 2014). Proposing locally relevant issues meaningful to these researchers, a series of seven statements were developed that these researchers felt would indicate if someone held pro-Aboriginal or anti-Aboriginal attitudes in the study sites.

The first of these statements was inspired by the work of Davis emphasising that Constitutional Recognition is an issue for all Australians (Davis \& Langton 2015). The statement aimed to assess acknowledgement of Aboriginal people: 'Aboriginal People should be recognised in the Australian constitution'. The second statement was derived from Beyond Blue's anti-racism television advertisement in Victoria that showed a vignette of individuals choosing not to sit next to an Aboriginal person on a bus and named it racist. The statement read: 'I would sit next to an Aboriginal person on a bus'. The third related to the research team's focus on health and questioned awareness of Aboriginal people's shorter life expectancy. It read: 'Aboriginal Australians do not live as long as non-Aboriginal Australians'. The fourth pursued perspectives of sameness from the literature (see McCallum 2003) as the researchers felt that sameness implies that culture is not relevant. To assess if people employed a sameness approach in their attitudes to Aboriginal people (who are different), the statement read: 'I treat all people the same, regardless of their race, skin-colour, gender or sexuality'.

The fifth statement drew on a recent incident at a football match in Victoria which had received major media attention in newspapers, on talk-back radio and in social media. The incident involved racist remarks from a young girl at the football match towards Aboriginal player Adam Goodes and her subsequent removal from the ground by security personnel. There was much public discussion and debate about her removal, her age and the remarks reflecting Adam Goodes as an ape, including that at her age she should not be held responsible, that they were just words, that the incident was harmless and that others had made similar comments. The statement in the questionnaire read: 'The incident involving Adam Goodes (football player \& Australian of the Year) was harmless'. It is important to note that the questionnaires were distributed prior to further incidents where Adam Goodes was booed by crowds, further booed when he responded with a war dance, and ultimately took leave from football because of stress.

The sixth statement aimed to bring racial issues into families and address more personal perspectives, acknowledging that for some individuals race is not a problem until it becomes part of their social network. Similar to other measures (see Dunn et al. 2003; Paradies et al. 
2008), the following statement was employed: 'I would worry if my son or daughter was in a relationship with an Aboriginal person'. The final statement challenged the myth of special privilege (McCallum 2003) and the researchers' experience of widespread belief of significant entitlements for Aboriginal people. This read 'Aboriginal people receive more benefits from the government than non-Aboriginal people'. Respondents were asked to agree or disagree with each of these statements on a five point Likert scale. It was initially hypothesised that individuals with pro-Aboriginal attitudes would support Constitutional recognition, would sit next to an Aboriginal person on a bus, were aware of a shorter life expectancy, did not treat everyone the same, did not think the Adam Goodes incident was harmless, would not worry if their child was in a relationship with an Aboriginal person and did not think Aboriginal people received more benefits. However, it became apparent that interpretations of some statements, including constitutional recognition, sameness and special privilege, were unclear.

In addition to the statements above, respondents were also asked questions about their awareness of racism. The first of these questions asked 'do you think racism exists locally?' (yes/no) and if yes, 'who do you think experiences racism locally?' as an open-ended question. The next question asked if respondents had ever observed a racial incident (yes/no). Finally, to pursue local knowledge, all were asked to 'please name the traditional owners of your area'. Around these questions and the seven statements, many unsolicited comments were written that explained answers or expressed opinions. Because of the frequency of these comments, they were included for analysis.

Data were entered into an electronic database and analysed with the assistance of SPSS (version 22). Frequencies, crosstabs, Chi square and correlations (Pearson's r) were used to examine association between different variables. Cronbach's alpha and factor analysis were conducted on the seven items to explore which statements were of similar dimensions. In addition, comments written on questionnaires were also coded, categorised and presented.

\section{Findings}

A total of 1,244 non-Aboriginal respondents completed and returned the questionnaire. More respondents were from Shepparton (see Table 1). Importantly, the average age of participants was 60 years, indicating an older sample than the population of these Shires. In 
addition, respondents were more likely to be male (60\%). Comparison with Census data suggests that education levels were similar while incomes were lower among this sample than for the population as a whole. Other than in Shepparton, the proportion of respondents born in Australia was higher than recorded in the Census (ABS, 2011). Together, this suggests that our sample was older, more often male and had lower incomes than the populations of these Shires. It is also important to note that these regions tend to be politically conservative, and while this was not asked about, political values based on election results in these shires tend to be more conservative than for other areas of Victoria.

\section{TABLE 1 HERE}

Respondents were asked to agree or disagree with seven statements. The frequency of respondents who agreed with each statement is presented in Table 2. Around two-thirds agreed that Aboriginal people should be recognised in the constitution, Aboriginal people do not live as long as non-Aboriginal Australians and that Aboriginal people receive more benefits. Most of those not agreeing with these statements indicated the midpoint and so did not disagree either. Nine of every ten respondents indicated that they would sit next to an Aboriginal person on a bus and $86 \%$ indicated that they treat all people the same, regardless of race, skin-colour, gender or sexuality. More respondents reflected anti-Aboriginal sentiments on the statements about the Adam Goodes incident (young girl's racist remarks) and where Aboriginal relations entered their own family. While three in ten thought the incident was harmless, four in ten disagreed. Around a quarter would worry if their son or daughter was in a relationship with an Aboriginal person while half indicated they would not worry.

\section{TABLE 2 HERE}

When asked about racism locally, 55\% reported that racism exists locally. This ranged from $72 \%$ among Shepparton respondents to $51 \%$ in Moira, $43 \%$ in Wangaratta and $39 \%$ in Goldfields; this difference was statistically significant. In most regions, around onethird said they had observed a racial incident, again higher among Shepparton respondents $(41 \%)$. This suggests that racism is known to exist, observed by many and yet continues.

Respondents were also asked to name 'the traditional owner group' in their local area. A total of $25 \%$ of all participants listed a traditional owner group. This statistically significant difference between shires found $37 \%$ of Shepparton respondents naming a 
traditional owner group, $31 \%$ of Moira respondents, $22 \%$ of Wangaratta participants and only $3 \%$ of Central Goldfields respondents. Overall, $10 \%$ responded that they did not know who the traditional owners were and 51\% did not answer the question. A further $7 \%$ reported that 'I don't believe in this' or 'who cares' while another 2\% indicated 'all Australians' and 1\% wrote a racist remark.

These questions incited a range of emotive comments written on the questionnaire. In no other section of the questionnaire were comments written, but many respondents had written (often in capital letters) in the margins, under questions or on the back cover about Aboriginal people/issues (see Table 3). For some, specific questions triggered a strong response, particularly for those with negative feelings towards Adam Goodes or those thinking Aboriginal people receive special treatment: 'providing no favouritism to them!' Interestingly, others added positive comments about Aboriginal people, diverse cultures or that 'no person of any colour or race should [be] subject to racism'. Still others commented that these questions 'should not be in a health survey' or drew on discourses of sameness to remark 'we are all Australians/the same'. Another eight gave detailed stories of how White people had been subjected to abuse by Aboriginal people. Embedded in these comments were discourses of special privilege, sameness, awareness of racism and new racisms: 'racism is fairly hidden these days'.

\section{TABLE 3 HERE}

The seven attitudinal items yielded a Cronbach's Alpha of .19, indicating a minimal internal consistency between the items. A factor analysis confirmed that these items measure different dimensions. The seven items yielded three factors that together explained $62 \%$ of the variance. Five of the items contributed to the first factor (recognition in constitution, sitting next to an Aboriginal person on a bus, treating all people the same, not being worried if their child was in a relationship with an Aboriginal person and not believing Aboriginal people receive more benefits) and these explained $30 \%$ of the variance. The second factor explained $18 \%$ of the variance and three items contributed: believing the Adam Goodes incident was harmless, treating all people the same and Aboriginal people receiving more benefits. Two items contributed to the third factor (Aboriginal people do not live as long and worrying if their child was in a relationship with an Aboriginal person) which explained $14 \%$ of the variance but seemed to reflect both pro- and anti-Aboriginal attitudes. Cronbach's alpha for the items in each factor also failed to indicate internal consistency $(0.04,0.20$ and 
0.01 for the items in factors 1,2 and 3 respectively). Thus these seven statements highlight that there are different and inconsistent attitudes towards Aboriginal people/issues.

To explore these attitudes in more detail, a correlation matrix between the seven measures of attitudes towards Aboriginal people/issues identified statistically significant associations between some of the statements, although the strength of correlations varied (see Table 4). Strong correlations identified that respondents who indicated they would 'sit next to an Aboriginal person on a bus' were more likely to agree that 'Aboriginal people should be recognised in the Australian constitution' and they 'treat all people the same'. Some statements were not correlated with others, including 'Aboriginal Australians do not live as long' and 'the incident involving Adam Goodes was harmless'. For others, the strength of the correlations was low. In addition, the question asking if racism exists locally did not yield a statistically significant correlation with any of the measures of attitudes towards Aboriginal people. This suggests respondents were not consistent in their attitudes towards Aboriginal people and negative/positive responses to some items did not yield negative/positive responses to others.

\section{TABLE 4 HERE}

When correlating responses to the attitudinal statements with demographic characteristics of respondents (gender, age, education, income, length of residence, rurality, those born in Australia and English as a first language) to identify who is more likely to hold pro- or anti-Aboriginal attitudes, there was no correlation of 0.2 or more. There was a statistically significant correlation between education and the incident involving Adam Goodes where those completing secondary school were less likely to agree the incident was harmless $\left(\mathrm{r}=-0.19^{*}\right)$. All other statistically significant correlations were not strong $(<+/$ 0.15). However, the item identifying that racism exists locally was correlated with age ( $\mathrm{r}=$ $\left.0.22^{*}\right)$, income $\left(\mathrm{r}=-0.17^{*}\right)$ and education $\left(\mathrm{r}=0.16^{*}\right)$ where younger respondents with lower incomes and higher education were more likely to agree racism exists locally.

Among responses to the seven attitudinal items, there was small variation across sites (see Table 2). A statistically significant difference across the shires was identified in the statements Aboriginal people do not live as long (slightly lower in Goldfields) and I treat all people the same (see Table 2). Correlations between the attitudinal items and demographic characteristics were also conducted for each of the four shires separately. In Shepparton, there were no consistent statistically significant correlations between the demographic 
questions and the measures of attitudes towards Aboriginal people. In Moira Shire, age and income were associated with the statement 'Aboriginal people should be recognised in the constitution', $(\mathrm{r}=0.24 *$ and $\mathrm{r}=-0.27 *$ respectively), suggesting that Moira residents who are older and on lower incomes are more likely to agree with constitutional recognition. Residents of Moira with at least a Year 12 education were more likely to disagree that the incident involving Adam Goodes was harmless $\left(\mathrm{r}=-0.25^{*}\right)$ and they would worry if their child was in a relationship with an Aboriginal person $\left(r=-0.25^{*}\right)$. In Wangaratta, respondents with higher incomes and education levels were more likely to agree that Aboriginal Australians do not live as long $\left(r=0.22^{*}\right.$ and $r=0.20^{*}$, respectively). Those with higher education were also less likely to agree that the incident involving Adam Goodes was harmless $(r=-0.29 *)$ and they would worry if their child was in a relationship with an Aboriginal person $\left(r=-0.19^{*}\right)$. In Central Goldfields, those who had lived in the community longer, were older and had lower formal education were more likely to agree that they would worry if their child was in a relationship with an Aboriginal person $\left(\mathrm{r}=0.33^{*}, \mathrm{r}=0.22^{*}\right.$ and $\mathrm{r}=$ $-0.21 *$, respectively). Central Goldfields respondents who had lived in the community were also more likely to agree that Aboriginal people receive more benefits $\left(\mathrm{r}=0.20^{*}\right)$. Thus there are relationships between education, age, income and length of residence for particular items in some sites. This suggests that attitudes towards Aboriginal people/issues vary in the type of attitude, in specific locations and for some individuals.

\section{Discussion}

The findings of this analysis indicate that attitudes towards Aboriginal people are multidimensional and inconsistent (VicHealth 2014; Forrest \& Dunn 2006; Dunn \& McDonald 2001). The study found that there was diversity in attitudes towards Aboriginal people, with some respondents being supportive of some issues while holding negative attitudes in other ways. Few clear patterns of who holds specific attitudes were identified and analysis at the shire level highlighted the complexity of attitudes towards Aboriginal people/issues. AntiAboriginal attitudes were expressed by many respondents in some ways which is likely to have implications for the health and wellbeing of Aboriginal people living in these four shires (see Paradies et al. 2008).

Consistent with previous studies, many respondents in this study were aware racism occurs and had observed racial incidents (Beyond Blue 2014; City of Greater Shepparton 2011). That the Adam Goodes incident sparked the most unsolicited comments implies a 
superficiality of relations between Aboriginal and mainstream Australia. This is a far cry from non-Aboriginal Australians trying to understand cultural differences and build relationships (Maddison 2011). Rather, responses reflected new racisms that reproduced stereotypes, expectations of normalised behaviour and/or discourses of sameness in diverse and complex ways (see Bourke \& Geldens 2007; Nelson, 2013).

While two thirds indicated that Aboriginal Australians should be formally recognised in the Australian constitution, few disagreed. These results do not identify if the majority of respondents support the proposal in principal or agree with specifics of the proposal. Aboriginal writers suggest that the current proposal refers to 'soft', rather than 'strong' constitutional recognition (Davis \& Langton 2015) but it is unclear if Australians want a stronger form of recognition. Given the lack of disagreement and few unsolicited comments about this statement, findings imply Davis and Langton's (2015) position that mainstream Australia are not engaging in debate about the nation's constitution.

While almost two-thirds of respondents were aware that Aboriginal Australians do not live as long as non-Aboriginal Australians (see Bronwen et al. 2014; Carey \& Crammond 2014), one-third seemed unaware of the health, lives and struggles of Aboriginal people. Like other studies, two-thirds believed that Aboriginal Australians receive more benefits than non-Aboriginal Australians (see Pedersen et al. 2006; Beyond Blue 2014) which underpins the discourse of special treatment (McCallum 2003). Like previous studies (Dunn et al 2003; Paradies et al. 2008), the statement about one's son/daughter being in a relationship with an Aboriginal person identified a quarter of respondents would worry about Aboriginal issues in their own family. This distinguishes structural issues or race relations removed from the personal to one that confronts the immediate family.

Of all the questions about racial attitudes, the item yielding the least anti-Aboriginal responses was sitting next to an Aboriginal person on a bus. Respondents may have been more reluctant to disagree with this statement as it had been publicly named as racist and few people wish to be thought of as racist (Blum 2002). However, the statement about the racial incident involving Adam Goodes identified that racial incidents are viewed by some as harmless, supporting Nelson's (2014) discourse of deflection (this is an isolated incident). This was also the issue stirring the most unsolicited comments. Such incidents, when not clearly named as racism, bring strong emotions to the fore; comments contradicted Goodes naming the incident as racist, rejected behaviours different to the cultural norm and gave rise 
to expressions of old racisms. This blends discourses of denial, temporal deflection and deflection from the mainstream (see Nelson 2014). As Hage (2014) suggests, while many Australians are anti-racist in principle, incidents ignite more racial views and these are rarely resolved.

The statement 'I treat all people the same' resulted in general agreement, suggesting respondents identified agreeing was a positive response. An intention to treat all people equitably undermines difference and obscures culture by treating all people the same (see McCallum 2003). Agreement with this statement infers a discourse of sameness yet disagreement with this statement may also suggest treating some people better than others. Interestingly, agreeing with this statement was positively correlated with other proAboriginal views. Thus the statement contains many meanings and highlights the complexity of racial attitudes and the difficulty of measuring them (see Harrell 2000).

What this study did find is that despite measuring attitudes towards Aboriginal people in different ways, there was a lack of consistency between these attitudes. Many of the items did not strongly correlate, there was little internal consistency and the seven items were found to yield different attitudinal dimensions. This suggests there are different ways of thinking about Aboriginal people and that attitudes among non-Aboriginal people are embedded with multiple discourses. It concurs with literature about new racisms that are more subtle and complex while also more difficult to challenge (Forrest and Dunn 2007; Nelson 2014).

Furthermore, there were few demographic characteristics correlated with any of these attitudes although education, age, income and length of residence were at times associated with specific attitudinal items in some locations. Previous studies have found age, education and gender to be related to some attitudes, albeit inconsistently (Pedersen et al. 2004). Again, this highlights the complexity of racism and that particular individuals may be supportive of Aboriginal people in some respects but not in other ways. The implication is that Aboriginal people cannot predict unsafe spaces or arenas where racism may be more frequent or with whom interactions are likely to be negative. Anticipating experiences of racism can result in a heightened sense of awareness, anxious feelings and a 'chronic anticipatory state to prepare for the possibility of a racist threat or situation' (James 2015; Mwendwa et al. 2011: 595). Further, it makes anti-racist campaigns more difficult as particular attitudes or individuals cannot be targeted. These complex and subtle new racisms strengthen their pervasiveness (Forrest \& Dunn 2007). 
The analysis did find subtle place-based differences between the four sites. Residents of Greater Shepparton were more aware of racism and were more likely to have observed a racial incident, most likely because the Aboriginal population is visible in Shepparton. For similar reasons, Shepparton respondents were more likely to name a traditional owner group while very few respondents from Central Goldfields named traditional owners. However, while Shepparton respondents were more aware, their attitudes were not more proAboriginal. Furthermore, the types of people expressing negative relationships varied in the different sites for some attitudes. As Nelson (2014: 68) highlighted, spatial deflections, judgement of cultural expression and critique of those who challenge racism and how they challenge it are used to justify ongoing racism in particular areas. These findings supports the proposition that racism is 'everywhere different' (Dunn \& McDonald 2001) and call for localised anti-racism campaigns (Nelson 2014).

This study has limitations in that respondents were older and not representative of the population. Further, seven statements have attempted to measure complex racial attitudes and, consequently, interpretations are unclear. Future research could explore in more detail the role of place and individual characteristics in the re/production of racial attitudes. Additionally, the development of adequate measures of racism and raical attitudes for Australian contexts could enhance understanding. However, given the significant number of questionnaires analysed, some general trends can be identified.

\section{Conclusion}

This study has found that new racisms, those which are subtle, complex and confusing are in operation (see Cunneen et al. 2014; Forrest \& Dunn 2007; Gainous 2012; Hage 2014; Nelson 2013). The lack of correlations between different attitudes towards Aboriginal people/issues suggests that non-Aboriginal Australians vary in their attitudes, knowledge and understandings. Once named as racism, respondents were less likely to identify with them, while in other un-named scenarios, more respondents could justify disrespectful attitudes. There were also few associations between demographic characteristics and these attitudes, indicating that individuals who are more likely to hold negative attitudes towards Aboriginal people varies by place and attitude. The challenge of negotiating these complexities for Aboriginal Australians, not knowing who or in what way negative sentiments will be expressed but knowing negative attitudes are likely to be expressed, makes daily life challenging. This suggests that public acknowledgment of, and local action in response to 
racism is applicable to all four shires (see Nelson 2013). Rather than identifying certain places as 'racist', it is important to acknowledge that racism is 'everywhere different' (Dunn $\&$ McDonald 2001) and 'all communities can undertake initiatives to address racism' (Nelson 2014: 81).

Larson et al. (2007: 328) argued that: 'Without fundamental changes in how members of the dominant Australian culture behave towards Aboriginal people, initiatives to improve health services, educational and employment opportunities may have limited impact on health inequalities. The broader Australian community is told that Aboriginal Australians are in crisis (see Slater 2008), however, the focus for action remains on Aboriginal Australians. This study highlights the critical role that non-Aboriginal Australia plays in determining outcomes of Aboriginal Australians. It is our conclusion that the many varied understandings of racial attitudes allow new racisms, including discourses of sameness, special privilege and exclusion, to be maintained. The onus, we suggest, is on non-Aboriginal Australia to take responsibility for its privileged status, to address social inequity and to challenge discourses of racism.

\section{Acknowledgments}

The authors would like to thank all the residents of these four shires who completed our questionnaire. We also acknowledge the Australian Government Department of Health for funding through the Rural Health Multidisciplinary Training programmes.

\section{References}

Beyond Blue. (2014) Discrimination against Indigenous Australians: A snapshot of the views of non-Indigenous people aged 25-44, Retrieved from https://www.beyondblue.org.au/docs, Beyond Blue.

Blum, L. (2002) 'Racism: What it is and What it isn't', Studies in Philosophy and Education, $21(3), 204-18$.

Bourke, L. \& Geldens, P. (2007) 'Perceptions of Reconciliation and related Indigenous Issues among Young Residents of Shepparton', Australian Journal of Social Issues, 42 (4), 603-21. 
Bronwen, P., Morrell, S., Taylor, R. \& Daniels, J. (2014) 'A review of life expectancy and infant mortality estimations for Australian Aboriginal people', BMC Public Health, 14 (1), 1-19.

Carey, G. \& Crammond, B. (2014) 'Help or hindrance? Social policy and the 'social determinants of health', Australian Journal of Social Issues, 49 (4), 489-507.

City of Greater Shepparton (2011) Aboriginal experiences of racial discrimination survey, Shepparton, City of Greater Shepparton.

Cunneen, C., Allisson, F. \& Schwartz, M. (2014) 'Access to justice for Aboriginal People in the Northern Territory', Australian Journal of Social Issues, 49 (2), 219-40.

Davis M. \& Langton, M. (eds) (2015) It's Our Country, Melbourne, Melbourne University Press.

Deitch, E., Barsky, A., Butz, R., Chan, S., Brief, A. \& Bradley, J. (2003) 'subtle yet significant: the existence and impact of everyday racial discrimination in the workplace', Human Relations, 56 (11), 1299-1324.

Dillman, D.A. (2000) Mail and Internet Surveys: The Tailored Design Method, $2^{\text {nd }}$ Ed., New York, John Wiley.

Dunn, K.M. \& McDonald, A. (2001) 'The geography of racisms in NSW', Australian Geographer 32 (1), 29-44.

Dunn, K. \& Geeraert, P. (2003) 'The geography of 'race' and racisms', Geodate 16 (3): 1-6.

Dunn, K., Forrest, J., Burnley, I. \& McDonald, A. (2004) 'Constructing racism in Australia', Australian Journal of Social Issues, 39 (4), 409-30.

Dunn, K. \& Nelson, J.K. (2011) 'Challenging the public denial of racism for a deeper multiculturalism', Journal of Intercultural Studies, 32 (6), 587-602.

Forrest, J.\& Dunn, K. (2007) 'Constructing Racism in Sydney, Australia’s Largest EthniCity', Urban Studies, 44 (4), 699-721.

Gainous, J. (2012) 'The New “New Racism” Thesis', Journal of Black Studies, 43 (3), 25173. 
Grattan, M. (ed.) (2000) Reconciliation, Melbourne, Bookman Press.

Hage, G. (2014) 'Continuity and change in Australian racism', Journal of Intercultural Studies, 35 (3), 232-7.

Harrell, S. (2000) A multidimensional conceptualization of racism-related stress: implications for the well-being of people of color', American Journal of Orthopsychiatry, 70 (1), 42-57.

Henry, B.R., Houston, S. \& Mooney, G.H. (2004) 'Institutional racism in Australian healthcare: a plea for decency', Medical Journal of Australia, 180 (10), 517-20.

James, T. (2015) 'Stress, anxiety and perseverative cognition among Aboriginal people', paper presented to the Ngar-wu Wanyarra Aboriginal Health Conference, Shepparton, 16-17 April.

Jordan, K., Bulloch, H. \& Buchanan, G. (2010) 'Statistical equality and cultural difference in Indigenous wellbeing frameworks: A new expression of an enduring debate', Australian Journal of Social Issues, 45 (3), 333-62.

Larson, A., Gillies, M., Howard, P. \& Coffin, J. (2007) 'It's enough to make you sick: the impact of racism on the health of Aboriginal Australians', Australian and New Zealand Journal of Public Health, 31 (4), 322-9.

Maddison, S. (2011) Beyond White Guilt, Sydney, Allen \& Unwin.

McCallum, K. (2003) 'Walking and talking reconciliation', Australian Journal of Communication, 30 (2), 115-32.

Mwendwa, D., Sims, R., Madhere, S., Thomas, J., Keen, L. Callender, C. \& Campbell, A. (2011) 'The influence of coping with perceived racism and stress on lipid levels in African Americans', Journal of the National Medical Association, 103 (7), 594-601.

Nelson, J. (2013) 'Denial of racism and its implications for location action', Discourse \& Society, 24 (1), 89-109.

Nelson, J. (2014) 'Place-defending and the denial of racism', Australian Journal of Social Issues, 49 (1), 67-85. 
Paradies, Y. (2006) 'A systematic review of empirical research on self-reported racism and health', International Journal of Epidemiology, 35 (4), 888-901.

Paradies, Y., Harris, R., \& Anderson, I. (2008) 'The impact of racism on Indigenous health in Australia and Aotearoa: Towards a research agenda', Discussion Paper No. 4, Darwin, Cooperative Research Centre for Aboriginal Health and Flinders University.

Paradies, Y.(2016) 'Attitudinal barriers to reconciliation in Australia'. In S. Maddison, T. Clark \& R. de Costa (eds.) The Limits of Settler Colonial Reconciliation: NonIndigenous People and Responsibility to Engage, Melbourne, Springer.

Pedersen, A., Griffiths, B., Contos, N., Bishop, B. \& Walker, I. (2000) 'Attitudes toward Aboriginal Australians in City and Country Settings', Australian Psychologist, 35 (2), 109-17.

Pedersen, A., Beven, J.P., Walker, I. \& Griffiths B. (2004) 'Attitudes towards Indigenous Australians: The role of empathy and guilt', Journal of Community and Applied Social Psychology 14 (4): 233-49.

Pedersen, A., Clarke, S., Dudgeon, P. \& Griffiths, B. (2005) 'Attitudes towards Indigenous Australians and asylum seekers: The role of false beliefs and other social-psychological variables', Australian Psychologist, 40 (3), 170-8.

Pedersen, A., Dudgeon, P., Watt, S. \& Griffiths, B. (2006) 'Attitudes toward Indigenous Australians: The issue of 'special treatment' ', Australian Psychologist, 41 (2), 85-94.

Slater, L. (2008) ' 'Aurukun, we're happy, strong people’: Aurukun kids projecting life into the headlines', Borderlands E-Journal: New Spaces in the Humanities, 7 (2), 1-14.

VicHealth (2014) 'Findings from the 2013 survey of Victorians' attitudes to race and cultural diversity', Melbourne, Victorian Health Promotion Foundation.

Walker, I. (2001) 'Changes in prejudice against Aboriginal Australians'. In M. Augoustinos \& K.J. Reynolds (eds.), Understanding Prejudice, Racism and Social Conflict, London, Sage.

Wise, A. (2010) 'Sensuous multiculturalism: Emotional landscapes of Inter-ethnic living in Australian suburbia', Journal of Ethnic and Migration Studies 36 (6): 917-37. 
Wyatt, S., Williams, R., Calvin, R., Henderson, F. Walker, E. \& Winters, K. (2003) 'Racism and cardiovascular disease in African Americans', The American Journal of the Medical Sciences, 325 (6), 315-31.

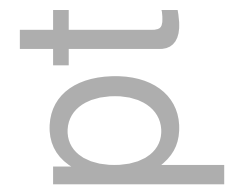

Table 1: Demographic characteristics of questionnaire respondents

\begin{tabular}{lccccc}
\hline & $\begin{array}{c}\text { Greater } \\
\text { Shepparton }\end{array}$ & $\begin{array}{c}\text { Moira } \\
\text { Shire }\end{array}$ & $\begin{array}{c}\text { City of } \\
\text { Wangaratta }\end{array}$ & $\begin{array}{c}\text { Central } \\
\text { Goldfields }\end{array}$ & Total \\
\hline Number of questionnaires & 465 & 229 & 271 & 279 & 1244 \\
Male (\%) & 62 & 60 & 57 & 60 & 60 \\
Age (median) & 58 & 60 & 60 & 62 & 60 \\
Completed Year 12+ (\%) & 48 & 46 & 46 & 40 & 46 \\
Earning under \$800/week (\%) & 53 & 58 & 66 & 70 & 60 \\
Born in Australia (\%) & 83 & 90 & 89 & 90 & 87 \\
English as 1st language (\%) & 89 & 96 & 95 & 96 & 93 \\
Median length residence, yrs & 37 & 26 & 35 & 30 & 32 \\
& & & & & \\
Rurality & & & & 23 & 37 \\
$\%$ live in large town & 52 & 8 & 51 & 39 & 30 \\
$\%$ live in small town & 22 & 56 & 13 & 38 & 33 \\
\% live on property/farm & 26 & 36 & 36 & & \\
\hline
\end{tabular}

Table 2: Frequencies of respondents who agreed or strongly agreed with each of the statements about Aboriginal people/issues by Shire, in percent

\begin{tabular}{lccccc}
\hline Statement & $\begin{array}{c}\text { Greater } \\
\text { Shepp }\end{array}$ & $\begin{array}{c}\text { Moira } \\
\text { Shire }\end{array}$ & $\begin{array}{c}\text { City of } \\
\text { Wang }\end{array}$ & $\begin{array}{c}\text { Gold- } \\
\text { fields }\end{array}$ & Total \\
\hline Aboriginal People should be recognised in the & 60 & 65 & 71 & 70 & 66
\end{tabular}


Australian constitution.

I would sit next to an Aboriginal person on a bus.

89

88

92

92

89

Aboriginal Australians do not live as long as non-

62

65

65

57

62

Aboriginal Australians.

I treat all people the same, regardless of their

83

84

90

88

86

race, skin-colour, gender or sexuality.

The incident involving Adam Goodes (football

30

39

30

player \& Australian of the Year) was harmless.

I would worry if my son or daughter was in a

relationship with an Aboriginal person.

Aboriginal people receive more benefits from the

69

70

57

59

64 government than non-Aboriginal people.

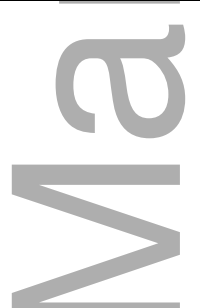

Table 3: Comments written on questionnaire about racism and racism questions

\begin{tabular}{lccccc}
\hline Shire & Wangaratta & Goldfields & Moira & Shepparton & Total \\
$\mathrm{N}$ & 271 & 217 & 229 & 465 & 1244 \\
\hline
\end{tabular}

Dislike for Adam Goodes

2

4

8

4

18

No special treatment

2

4

5

6

17

Positive comment

1

5

5

12

Racism not relevant to health

3

1

1

4

9

We are all Australians, level

3

2

4

9

playing field, no us and them 
offending White people

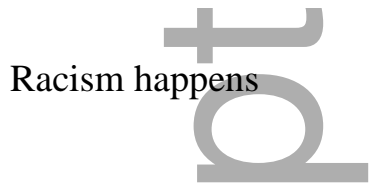

Talk of unacceptable

behaviours not race

Anti-welfare comment

Racism expressed about

migrants

Depends on family, re

son/daughter relationship

Other comment

Total comments
11

24
10

36
11

38
3

4

6

6

(1)

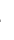

10

1

1

13

Table 4: Correlations between measures of attitudes toward Aboriginal people using Pearson's $r$
Statement
1
2
1. Aboriginal people should be recognised in the 1.0
Australian constitution.
2. I would sit next to an Aboriginal person on a $\quad .43^{*} \quad 1.0$
bus.

3

4

5

6

3. Aboriginal Australians do not live as long as $\quad .17^{*} \quad .14^{*} \quad 1.0$ 
non-Aboriginal Australians.

4. I treat all people the same, regardless of their $\begin{array}{lllll}.26^{*} & .52^{*} & .08^{*} & 1.0\end{array}$ race, skin-colour, gender or sexuality.

5. The incident involving Adam Goodes (football $\quad-.18^{*} \quad-.05 \quad-.05 \quad-.01 \quad 1.0$ player \& Australian of the Year) was harmless.

6. I would worry if my son or daughter was in a $\quad \begin{array}{llllll}-.13 * & -.22 * & .03 & -.20^{*} & .15^{*} & 1.0\end{array}$ relationship with an Aboriginal person.

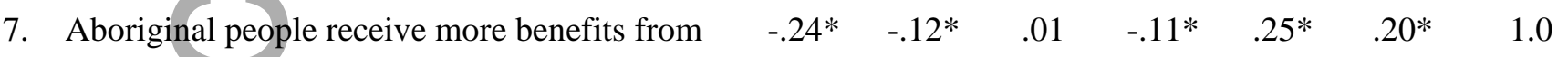
the government than non-Aboriginal people.

$* \mathrm{p}<.01$
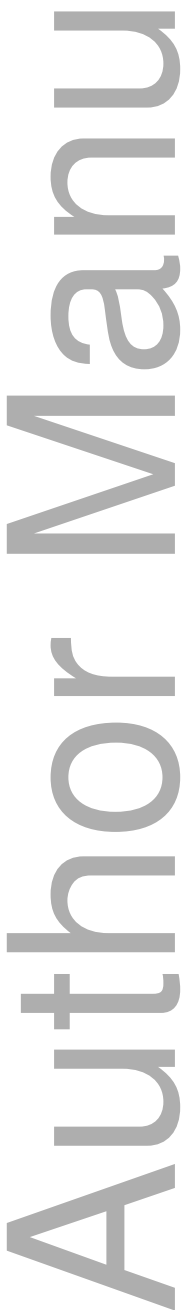


\section{University Library}

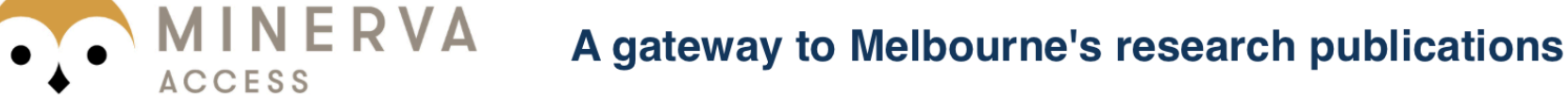

Minerva Access is the Institutional Repository of The University of Melbourne

Author/s:

Bourke, L;Malatzky, C;Terry, D;Nixon, R;Ferguson, K;Ferguson, P

Title:

Perspectives of Aboriginal issues among non-Aboriginal residents of rural Victorian communities

Date:

2017-09-01

Citation:

Bourke, L., Malatzky, C., Terry, D., Nixon, R., Ferguson, K. \& Ferguson, P. (2017). Perspectives of Aboriginal issues among non-Aboriginal residents of rural Victorian communities. AUSTRALIAN JOURNAL OF SOCIAL ISSUES, 52 (3), pp.278-293. https:// doi.org/10.1002/ajs4.16.

Persistent Link:

http://hdl.handle.net/11343/293339 